\title{
Youths' Opinions About Their Opportunities for Success in Coös County Communities
}

$\mathrm{T}$ The economic condition of youths' home communities may impact youth development, well-being, and expectations about the future. Many rural communities in the United States face economic vulnerabilities due to declines in traditional manufacturing, agriculture, and natural-resource extraction. The communities in Coös County, New Hampshire, in the northern most region of New Hampshire have been hit hard with the closing of several mills and other industries followed by the economic recession, leaving the county with the highest unemployment rate in the state. This fact sheet examines Coös County youths' beliefs about their access to educational and occupational opportunities in their home communities and whether these beliefs relate to their expectations for the future. To do so, we draw on the Coös Youth Study data collected in 2011 from 318 eleventh graders in the public schools. Although there is limited research to date, it can be argued that when adolescents perceive limited opportunities in their community, they may lower their own expectations for what is possible in the future.

\section{Perception of Opportunity}

We asked Coös youths to report their opinions about available educational and occupational opportunities in their communities. The answers on the Perception of Opportunity measure ranged from 1 (strongly disagree) to 5 (strongly agree). ${ }^{1}$ We explored the data separately for three regions of the county ${ }^{2}$ (see Figures 1 and 2). Overall, youths in Coös reported feeling more positive than negative about the opportunities available to them, but they do seem to acknowledge some concerns. For example, youths living in Region 3 (Berlin/Gorham), where some of the most significant job losses have occurred, reported less positive beliefs about their ability to work hard to get ahead and feel more strongly that they won't get ahead unless their family moves.

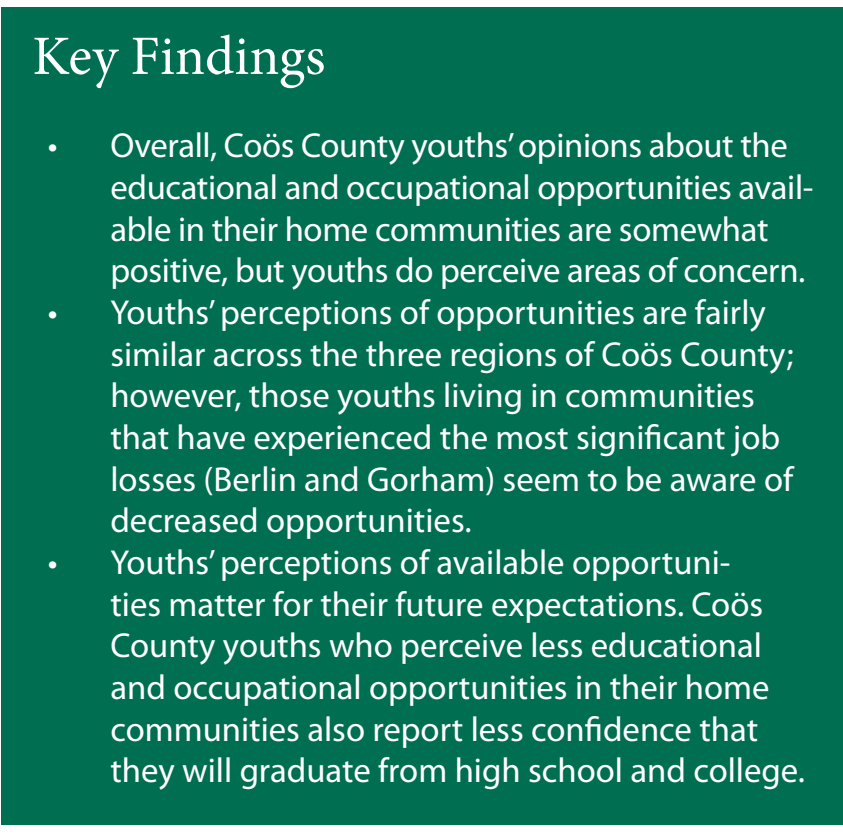

\section{Links Between Perception of Opportunity and Expectations for the Future}

To explore whether there was a link between youths' opinions about the availability of opportunities in their home communities and their expectations for the future, we looked at the links between overall perceptions of opportunities and youths' reports about the likelihood of finishing high school and college (see Figure 3). To do this, perceptions of opportunities were broken down into three levels: low perceptions of opportunities (105 youths), medium perceptions of

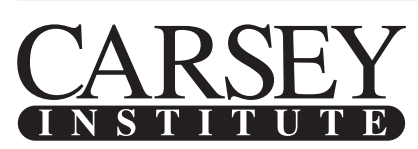

BUILDING KNOWLEDGE FOR FAMilies AND Communities
Huddleston Hall, 73 Main Street, Durham, NH 03824

(603) 862-2821 • www.carseyinstitute.unh.edu

This work was supported by the Neil and Louise Tillotson Fund of the New Hampshire Charitable Foundation. 
Figure 1: Perception of OpPortunity (Positive items) ${ }^{3}$

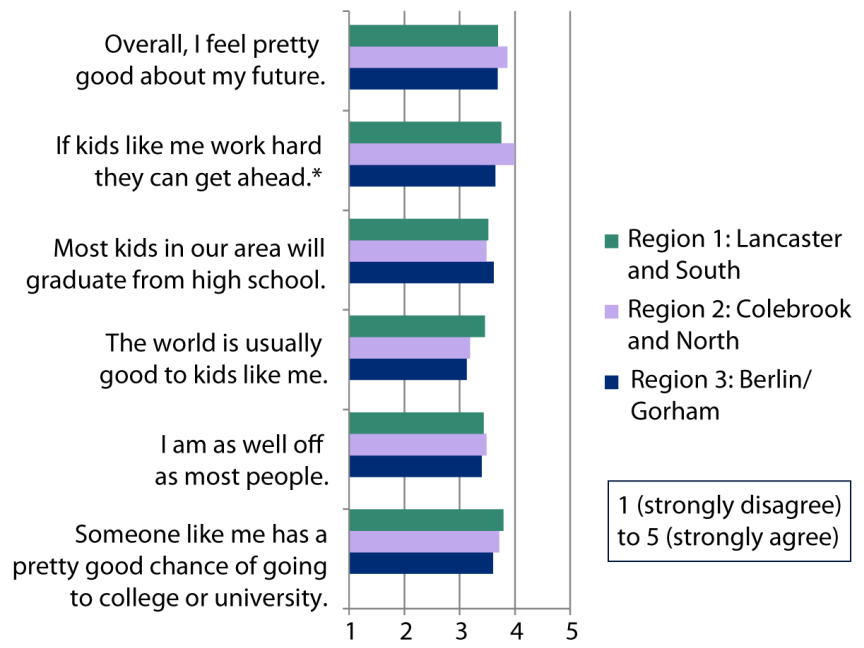

Figure 2: Perception of opportunity (Negative items)

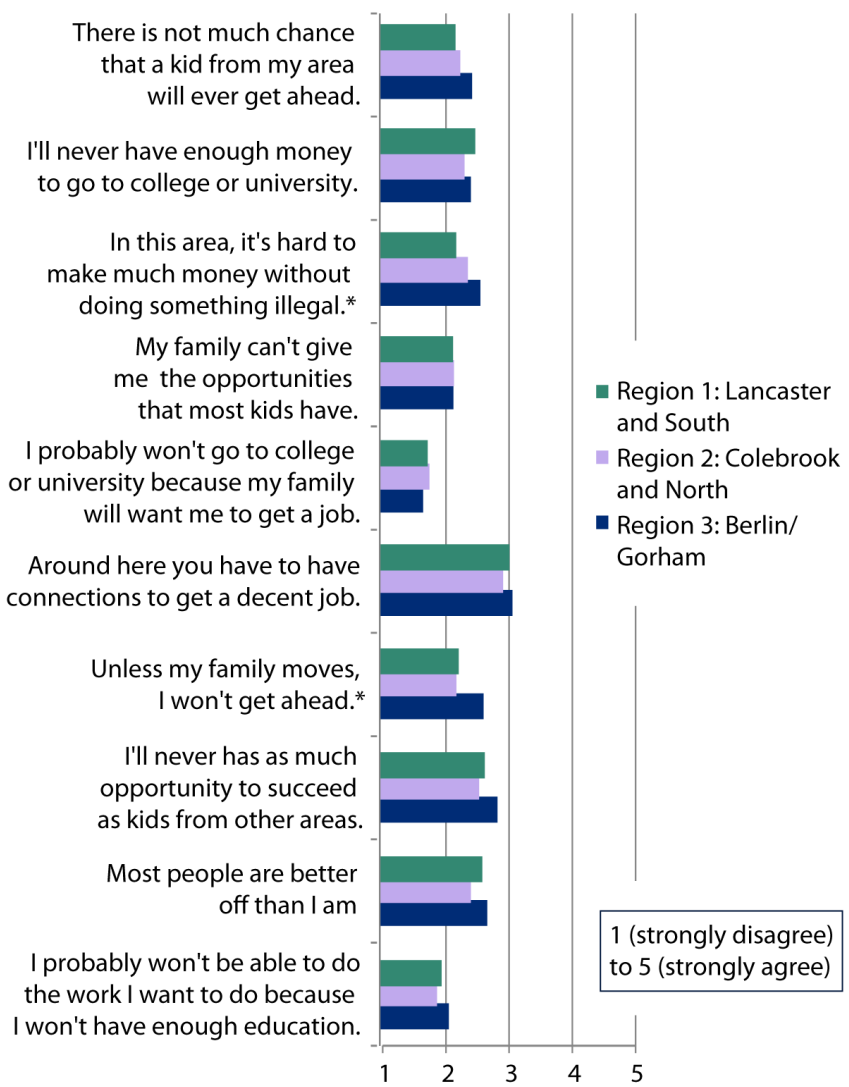

\section{ABOUT THE AUTHOR}

Erin Hiley Sharp, PhD, is a Carsey Institute faculty fellow and an asssistant professor in family studies at the University of New Hampshire (erin.sharp@unh.edu). opportunities (99 youths), and high perceptions of opportunities (114 youths), and the differences between opportunity groupings and youths' reported likelihood of finishing high school and college were tested. The answers on the likelihood of finishing high school and college items ranged from 0 (not at all likely) to 6 (very likely). Overall, the majority of Coös youths expect to finish both high school and college. However, youths' perceptions of opportunities in their home communities matter. Coös County youths who perceive less educational and occupational opportunities in their home communities also report less confidence that they will finish high school and college. These findings suggest that communities can have a positive impact on youths' futures if they can improve educational and job opportunities available to teens and help teens connect to existing opportunities. It will be important to continue to examine youths' beliefs about opportunities and expectations for the future as economic changes continue to take place in Coös County.

FIgURE 3: FUTURE EXPECTATIONS BY PERCEPTION OF OPPORTUNITIES

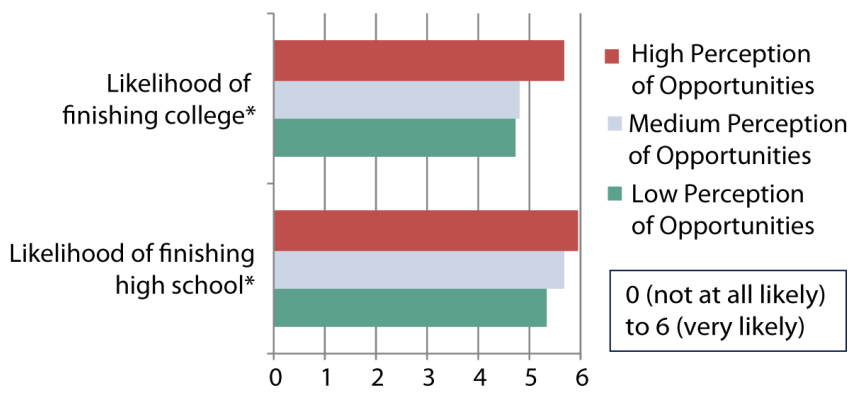

\section{E N D N O T ES}

1. J. Wall, K. Covell, and P. D. MacIntyre, "Implications of social supports for adolescents' education and career aspirations," Canadian Journal of Behavioural Science, 31 (1999): 63-71.

2. Route 2 serves as a geographical marker. Region 1: "Lancaster and South" includes students attending schools in the towns of Lancaster and Whitefield. Region 2: "Colebrook and North" includes schools in Colebrook, Pittsburg, Stewartstown, Stratford, and Groveton. Region 3: includes students attending schools in Berlin and Gorham.

3. In figures 1,2 , and 3 , if an item is followed by an asterisk, this indicates that differences are statistically significant.

\section{A C K N O W L E D G M E N T S}

This research is supported by the Neil and Louise Tillotson Fund of the New Hampshire Charitable Foundation and the Carsey Institute. The Rural Youth Study Team thanks the students participating in this research project and the superintendents, principals, guidance counselors, teachers, and administrators who helped the team collect these data. Thank you to Amy Sterndale and Laurel Lloyd for their editorial assistance. Also, special thanks to fellow members of the Rural Youth Research Team, including Eleanor Jaffee, Cesar Rebellon, Corinna Jenkins Tucker, and Karen Van Gundy. 